\title{
Case report of a solitary fibrofolliculoma on the alar rim
}

\author{
Ho Yoon Jeong ${ }^{1}$, \\ Yong Chan Bae ${ }^{1,2}$ \\ ${ }^{1}$ Department of Plastic and \\ Reconstructive Surgery, Pusan National \\ University School of Medicine, Busan; \\ ${ }^{2}$ Biomedical Research Institute, Pusan \\ National University Hospital, Busan, \\ Korea
}

Fibrofolliculoma is a benign tumor characterized by a smooth, dome-shaped papule of size 2-4 $\mathrm{mm}$. Most fibrofolliculomas occur as multiple lesions, and very rarely, they are solitary. Herein, we report a case of solitary fibrofolliculoma found in the alar rim, without the typical characteristics of a fibrofolliculoma. A 42-year-old man visited the hospital with a protruding lesion that had occurred 1 year previously. A mass of size $5 \times 7 \mathrm{~mm}$ was observed on the left alar rim. The tumor was dome-shaped and palpable. The patient did not have any similar lesions elsewhere. No family member was known to have such a lesion. An incisional biopsy was performed before surgery, and pathological examination revealed hyperkeratosis and dyskeratosis; however, an accurate diagnosis was not made. Complete resection was planned for the mass on the alar rim. The resected mass was subjected to permanent biopsy, and the pathological examination results led to the diagnosis of fibrofolliculoma. Therefore, when diagnosing a dome-shaped mass in the alar rim, despite the suspicion of a very rare disease, it is necessary to suspect fibrofolliculoma and consider the process from diagnostic examination to treatment.

Keywords: Hair diseases / Nose / Skin neoplasm

\section{INTRODUCTION}

Fibrofolliculoma is an autosomal dominant benign tumor characteristically found alongside the Birt-Hogg-Dube syndrome, involving trichodiscoma, acrochordon, multiple fibrofolliculomas, and internal neoplasms [1]. Most fibrofolliculomas are smooth papules with a dome shape, size of $2-4 \mathrm{~mm}$, and with multiple lesions occurring around the face [2]. Solitary fibrofolliculomas are rare. In 1984, Scully et al. [3] were the first to report a case of solitary fibrofolliculoma without genetic tendency and other skin lesions. However, only few cases have been reported since then. To the best of our knowledge, only 14 cases have been reported, of which two occurred in the nose (Table 1). However, none of these cases occurred in the alar rim [1,4-6].

Correspondence: Yong Chan Bae

Department of Plastic and Reconstructive Surgery, Pusan National University

School of Medicine, 179 Gudeok-ro, Seo-gu, Busan 49241, Korea

E-mail: baeyc2@hanmail.net

Received July 6, 2021 / Revised August 19, 2021 / Accepted August 20, 2021
Fibrofolliculoma is a rare disease, and it occurs either as multiple lesions or in association with genetic diseases such as BirtHogg-Dube syndrome; therefore, solitary fibrofolliculoma without other cutaneous abnormalities is extremely rare in clinical practice. Histological examinations have revealed the lesions to be clinical entities that lie somewhere between perifollicular fibroma and trichofolliculoma [7]; therefore, it is very difficult to distinguish these lesions from other pathologies. We herein present a case of a solitary fibrofolliculoma occurring in the alar rim of a healthy male and describe the treatment process and the pathology results.

\section{CASE REPORT}

A 42-year-old man presented to the hospital with a palpable mass, which had appeared a year ago, on his left alar rim (Fig. 1). The mass was $5 \times 7 \mathrm{~mm}$ in size, protruding and palpable, dome shaped, and the same color as that of his skin. He did not have 
Table 1. Previously reported cases of solitary fibrofolliculoma

\begin{tabular}{|c|c|c|c|c|c|}
\hline Author & Case & Age $(y r) / s e x$ & Location & Tumor size & Mass appearance \\
\hline Scully et al. [3] & 1 & $65 / F$ & Chin & $5 \mathrm{~mm}$ in diameter & Skin-to-pink colored, dome-shaped papule \\
\hline \multirow[t]{5}{*}{ Starink and Brownstein [5] } & 2 & $49 / \mathrm{M}$ & Chin & $5 \mathrm{~mm}$ in diameter & Yellowish nodule \\
\hline & 3 & $20 / F$ & Nose & & Skin-colored papule \\
\hline & 4 & $50 / M$ & Cheek & & Skin-colored papule \\
\hline & 5 & $60 / F$ & Ear & $3 \mathrm{~mm}$ in diameter & Dome-shaped papule \\
\hline & 6 & $52 / \mathrm{M}$ & Eyebrow & $6 \times 4 \mathrm{~mm}$ & \\
\hline Hong et al. [8] & 7 & $40 / F$ & Scalp & $7 \times 6 \times 5 \mathrm{~mm}$ & Skin-to-pink-colored papule \\
\hline Chang et al. [2] & 8 & $37 / F$ & Eyelid & $5 \times 5 \mathrm{~mm}$ & Skin-colored papule \\
\hline Cesinaro et al. [6] & 9 & $63 / F$ & Nose & $12 \times 10 \mathrm{~mm}$ & Skin-colored papule \\
\hline Cho et al. [9] & 10 & $45 / M$ & Ear & $12 \times 10 \times 8 \mathrm{~mm}$ & Flesh-colored mass \\
\hline Criscito et al. [10] & 11 & $72 / F$ & Cheek & $4 \mathrm{~mm}$ in diameter & Flesh-colored, dome-shaped papule \\
\hline Sohn et al. [11] & 12 & $50 / M$ & Posterior auricular region & $10 \times 12 \mathrm{~mm}$ & Flesh-colored papule \\
\hline Wang and Cheng [1] & 13 & $68 / F$ & Eyelid & $5 \times 5 \times 4 \mathrm{~mm}$ & Flesh-colored papule \\
\hline Mishra et al. [4] & 14 & $50 / M$ & Eyelid & $3 \times 3 \times 2 \mathrm{~cm}$ & \\
\hline
\end{tabular}

$\mathrm{M}$, male; F, female.

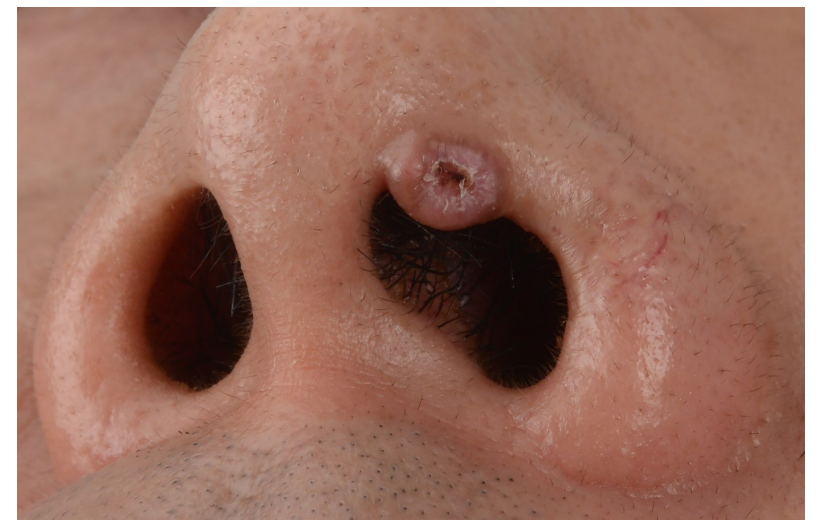

Fig. 1. A 42-year-old man with a $5 \times 7 \mathrm{~mm}$ mass on the left alar rim.

similar lesions in other areas of his body. In addition, none of his family members were known to have such a lesion. The patient had visited a local hospital before consulting in our clinic and had been diagnosed with keratoacanthoma. Under this diagnosis, incisional biopsy was performed on a portion of the mass for histological confirmation, along with the removal of the lesion. Pathologic examination revealed hyperkeratosis and parakeratosis, and complete excision was planned. Under local anesthesia, an elliptical incision was made to remove the lesion, including the mass. When viewed with the naked eye, no invasion of the mass into cartilage or other tissues was observed, and no adhesion to the periphery was observed. Therefore, the mass was considered to have been completely excised above the perichondrium. Permanent biopsy was requested for the excised mass, and nevus sebaceous was confirmed. We requested the pathology department for a review because it did not seem clinically correct, as nevus sebaceous is a congenital malformation that

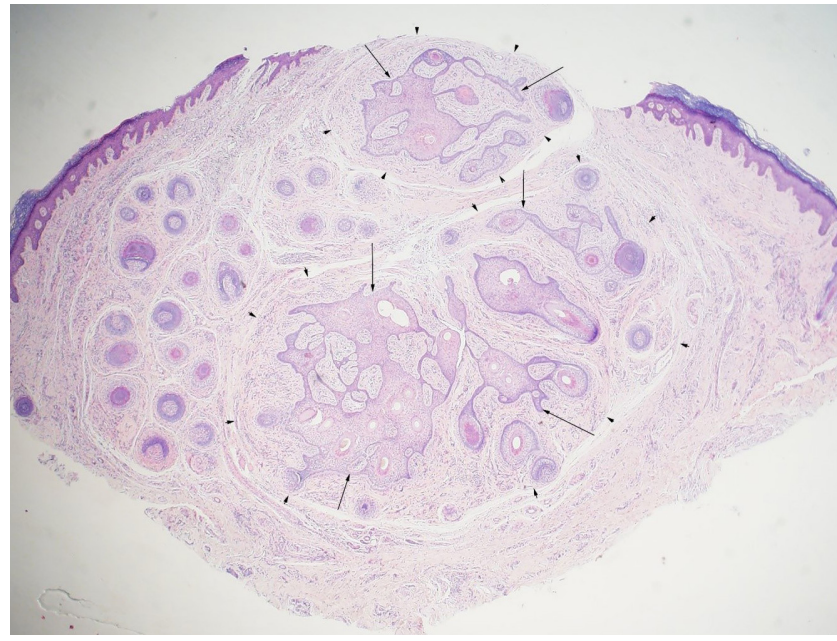

Fig. 2. Microscopic image of the lesion showing proliferative follicular epithelium (black arrows), surrounded by perifollicular fibrous tissue (black arrowheads) (H\&E, $\times 12.5)$.

can be found on the face [12]. Histological examination revealed the presence of proliferative follicular epithelium surrounded by perifollicular fibrous tissue (Fig. 2). Thin epidermal strands originated from the hair follicles and centered around the infundibulum of the hair. The connective tissue around the epithelium also showed sclerotic features (Fig. 3). Based on these pathological results, the final diagnosis was fibrofolliculoma.

\section{DISCUSSION}

Several tumors are formed in hair follicles [13-16]. Clinically, it is very difficult to distinguish fibrofolliculoma from trichodiscoma and perifollicular fibroma. When viewed with the naked 


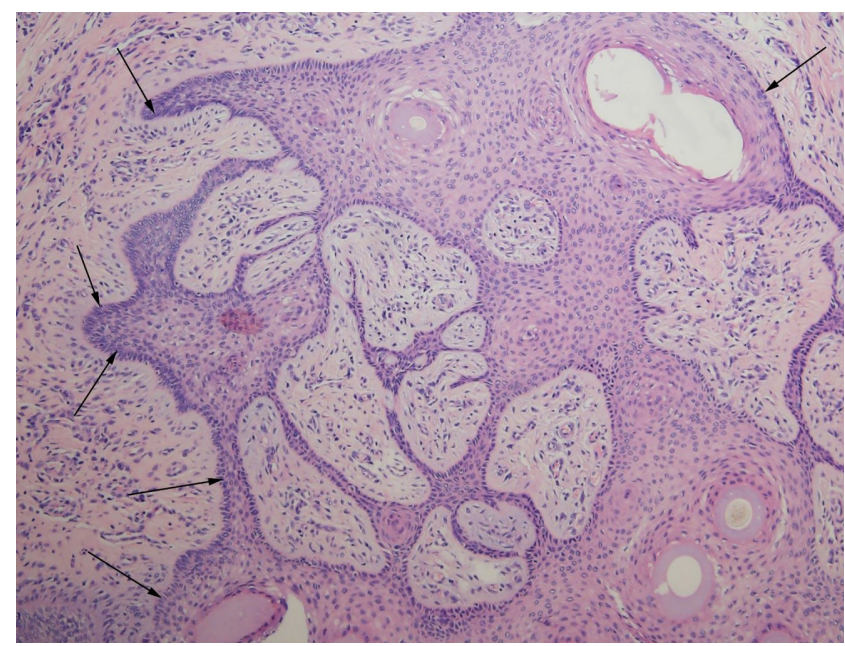

Fig. 3. Histopathological examination. Thin epidermal strands that originate from the hair follicle, and they are centered around the infundibulum of the hair. The connective tissue around the epithelium (black arrows) shows sclerotic features $(\mathrm{H} \& \mathrm{E}, \times 100)$.

eye, all these lesions are pale-yellow or white, $2-4 \mathrm{~mm}$ in size, usually dome shaped, and smooth [3]. Furthermore, according to the cases of solitary fibrofolliculoma reported thus far, most of them occurred in patients aged 50 years or older, and unlike multiple fibrofolliculomas, they do not show a genetic tendency and do not accompany other skin diseases [5]. To date, the only method for obtaining a definitive diagnosis of fibrofolliculoma is pathology. Therefore, diagnosis is made according to the pathological examination of an incisional biopsy and clinical judgment at presentation. In addition, solitary fibrofolliculoma is very rare; hence, there are not many clinical cases, and because it is difficult to distinguish between clinically similar types of perifollicular fibromas and trichodiscomas, it is highly likely to be misdiagnosed. Therefore, biopsy should be performed. Histologically, fibrofolliculoma is represented as a circular or oval-shaped well-bounded fibroepithelial proliferative tumor in the dermis, which appears as a concentric circle around the hair follicle. In the center of the tumor, epithelial proliferation of a single follicular infundibulum is generally observed and forms an epithelial zone that extends into the surrounding fibrous matrix, leading to unique network formation by anastomosis $[8,17]$. In this case, the lesion had thin epidermal strands centered around the infundibulum of the hair and the proliferative follicular epithelium, surrounded by connective tissue. In the case of multiple fibrofolliculomas, laser therapy using Erbium-YAG or $\mathrm{CO}_{2}$ and systemic isotretinoin administration are reportedly effective; nevertheless, treatment results vary [18]. Because of their rarity, there is no consensus on the treatment and prognosis of solitary fibrofolliculoma. Even though solitary fibrofolliculoma is known to be a benign mass, complete resection is considered desirable. In addition, as the protruding mass changes the shape of the alar rim, it was judged that complete resection is more desirable than other treatment methods to provide the patient a contouring effect for esthetic purposes. We report the diagnosis and treatment of a solitary fibrofolliculoma, a rare disease, in a healthy male with no specific medical history or family history of mass development in the nose. Fibrofolliculoma is a rare disease; however, when a mass occurs in the nose, clinicians should suspect fibrofolliculoma based on the clinical and histological characteristics presented in this case and consider treatment based on diagnostic tests and complete resection.

\section{NOTES}

\section{Conflict of interest}

Yong Chan Bae is an editorial board member of the journal but was not involved in the peer reviewer selection, evaluation, or decision process of this article. No other potential conflicts of interest relevant to this article were reported.

\section{Ethical approval}

The study was approved by the Institutional Review Board of Pusan National University Hospital (IRB No. 2106-018-104) and performed in accordance with the principles of the Declaration of Helsinki. Written informed consent was obtained.

\section{Patient consent}

The patient provided written informed consent for the publication and the use of his images.

\section{ORCID}

Ho Yoon Jeong https://orcid.org/0000-0003-1837-9146 Yong Chan Bae https://orcid.org/0000-0002-0268-4667

\section{Author contribution}

Conceptualization: YCB. Writing - original draft: HYJ. Writing - review \& editing: YCB, HYJ. Supervision: YCB.

\section{REFERENCES}

1. Wang W, Cheng J. Solitary fibrofolliculoma of the upper eyelid in a 68-year-old female: a case report. BMC Ophthalmol 2020; 20:97.

2. Chang JK, Lee DC, Chang MH. A solitary fibrofolliculoma in the eyelid. Korean J Ophthalmol 2007;21:169-71.

3. Scully K, Bargman H, Assaad D. Solitary fibrofolliculoma. J Am Acad Dermatol 1984;11(2 Pt 2):361-3. 
4. Mishra DK, Jakati S, Kaliki S. Solitary fibrofolliculoma of the eyelid: a less known entity. Indian J Pathol Microbiol 2021;64: 195-6.

5. Starink TM, Brownstein MH. Fibrofolliculoma: solitary and multiple types. J Am Acad Dermatol 1987;17:493-6.

6. Cesinaro AM, Rusev BC, Kutzner H. Fibrofolliculoma with ancient/pseudosarcomatous features. J Cutan Pathol 2010;37: 987-90.

7. Weintraub R, Pinkus H. Multiple fibrofolliculomas (BirtHogg-Dubé) associated with a large connective tissue nevus. J Cutan Pathol 1977;4:289-99.

8. Hong JK, Yoon DH, Kim TY, Kim HO, Kim CW. A case of solitary fibrofolliculoma. Ann Dermatol 1997;9:286-8.

9. Cho E, Lee JD, Cho SH. A solitary fibrofolliculoma on the concha of the ear. Int J Dermatol 2012;51:616-7.

10. Criscito MC, Mu EW, Meehan SA, Polsky D, Kopeloff I. Dermoscopic features of a solitary fibrofolliculoma on the left cheek. J Am Acad Dermatol 2017;76(2S1):S8-9.

11. Sohn KM, Woo YJ, Kim JE, Kang H. A solitary nodule on the posterior pinna. Indian J Dermatol Venereol Leprol 2019;85: 111-3.
12. Idriss MH, Elston DM. Secondary neoplasms associated with nevus sebaceus of Jadassohn: a study of 707 cases. J Am Acad Dermatol 2014;70:332-7.

13. Wee SJ, Park MC, Chung CM. Basal cell carcinoma misdiagnosed as trichoepithelioma. Arch Craniofac Surg 2020;21:2025.

14. Hu JL, Yoo H, Kwon ST, Kim S, Chung JH, Kim H, et al. Clinical analysis and review of literature on pilomatrixoma in pediatric patients. Arch Craniofac Surg 2020;21:288-93.

15. Choi JY, Cha WJ, Kwon HJ, Seo BF, Kwon H, Jung SN. A giant solitary vellus hair cyst on the nasal root. Arch Craniofac Surg 2020;21:326-8.

16. Koh IS, Cho HJ, Kim JW. Rapidly growing giant pilomatricoma in the right parotid region of a pregnant woman. Arch Craniofac Surg 2020;21:176-9.

17. Birt AR, Hogg GR, Dube WJ. Hereditary multiple fibrofolliculomas with trichodiscomas and acrochordons. Arch Dermatol 1977;113:1674-7.

18. Welsch MJ, Krunic A, Medenica MM. Birt-Hogg-Dubé syndrome. Int J Dermatol 2005;44:668-73. 